\title{
Root and leaf abscisic acid concentration impact on gas exchange in tomato (Lycopersicon esculentum Mill.) plants subjected to partial root-zone drying
}

\author{
Maria Valerio, Stella Lovelli, Adriano Sofo, Michele Perniola, Antonio Scopa, Marianna Amato \\ School of Agricultural, Forestry, Food and Environmental Sciences, University of Basilicata, Potenza, Italy
}

\begin{abstract}
Partial root-zone drying (PRD) is a deficit irrigation technique with great potential for water saving. A split-root experiment was conducted on tomato in controlled environment in order to test the response of two long-time storage cultivars to PRD. Ponderosa tomato, a cultivar with yellow fruits, was compared to Giallo tondo di Auletta, a local cultivar from southern Campania (Italy). Plants were subjected to three irrigation treatments: plants receiving an amount of water equivalent to $100 \%$ of plant evapotranspiration (V100); plants in which $50 \%$ of the amount of water given to V100 was supplied (V50); and plants where one root compartment was irrigated at $50 \%$ of water requirements and the other compartment was allowed to dry, and thereafter every side was rewetted alternatively (PRD). The highest levels of leaf abscisic acid (ABA) [on average equal to $104 \mathrm{ng} \mathrm{g}^{-1}$ fresh weight $\mathrm{FW}$ )] were measured in PRD and V50, at 70 days after transplantation. Root ABA concentration in both PRD and V50 reached mean values of $149 \mathrm{ng} \mathrm{g}^{-1} \mathrm{FW}$. There were differences for the irrigation regime in root $\mathrm{ABA}$ biosynthesis and accumulation under partial root-zone drying and conventional deficit irrigation (V50). Assimilation rate, stomatal conductance and intercellular $\mathrm{CO}_{2}$
\end{abstract}

Correspondence: Stella Lovelli, School of Agricultural, Forestry, Food and Environmental Sciences, University of Basilicata, via dell'Ateneo Lucano 10, 85100 Potenza, Italy.

Tel: +39.0971.205384 - Fax: +39.0971.205378.

E-mail: stella.lovelli@unibas.it

Key words: Lycopersicon esculentum; Partial root drying (PRD); Conventional deficit irrigation; Water use efficiency; ABA concentration.

Acknowledgements: the authors wish to thank Prof. Candido V. for invaluable scientific assistance and Mr. Giuseppe Mercurio for invaluable technical assistance.

Received for publication: 21 April 2016.

Revision received: 3 October 2016

Accepted for publication: 3 October 2016

(C) Copyright M. Valerio et al., 2017

Licensee PAGEPress, Italy

Italian Journal of Agronomy 2017; 12:788

doi:10.4081/ija.2016.788

This article is distributed under the terms of the Creative Commons Attribution Noncommercial License (by-nc 4.0) which permits any noncommercial use, distribution, and reproduction in any medium, provided the original author(s) and source are credited. concentration decreased in relation to the irrigation regime by 22 , 36 and $12 \%$, respectively, in PRD, V50 and V100 at 50 days after transplantation. Ponderosa variety accumulated $20 \%$ more dry matter than Auletta and significant differences were observed in leaf area. In both PRD and V50 of the two varieties, it was possible to save on average $46 \%$ of water. Our results indicate that there is still space to optimise the PRD strategy, to further improve the cumulative physiological effects of the root-sourced signaling system.

\section{Introduction}

The continuous raise in world population, combined with the increase in food consumption, especially in emerging countries, highlights the urgent need to produce more food to meet the growing demand. Agricultural fields irrigation plays and will continue to play a major role in food production and the livelihoods of the world's population. The availability of water varies considerably from region to region, and the competition for water can become very severe in arid and semi-arid areas. No economic sector uses as much water as agriculture, with an estimated value of $1300 \mathrm{~m}^{3}$ per person per year (de Fraiture et al., 2007). Due to climatechange related issues, in semi-arid Mediterranean areas, the frequency and severity of prolonged periods of drought may also increase in the future (Lovelli et al., 2012; Giorgi and Lionello, 2008). Hence, the need to apply innovative irrigation techniques able to increase the efficiency of water use is urgent. Research in the last two decades showed the importance of root-sourced chemical signals in modulating the growth and physiology of plants in drought conditions (Campos et al., 2009; Davies et al., 2002; Sauter et al., 2001). Results of these studies were applied to the development of innovative irrigation techniques known as deficit irrigation practices. One of these is the partial root-zone drying (PRD), consisting in keeping half of the root system near to field capacity, while the other half is under water deficit (Campos et al., 2009). In this way, only half of the root system is intermittently in dry conditions (Loveys et al., 2000) and triggers the production of abscisic acid (ABA), which in turn reduces leaf growth and stomatal conductance. At the same time, roots in the wet side of the soil take up enough water to maintain high leaf water potential in the leaves and sustain plant growth (Zegbe et al., 2006; Ahmadi et al., 2010). PRD irrigation technique has been shown to improve tomato water use efficiency (WUE) and fruit quality (Bravdo, 2005; Davies et al., 2000; Zegbe-Domínguez et al., 2003; Nardella et al., 2012). Notwithstanding, there is still little understanding on the mechanisms of PRD in different tomato cultivars, and therefore procedures for scheduling the optimum timing of irrigation for each root side still need research (Sepaskhan and Ahmadi, 2010). In this work, ABA levels in both roots and leaves were analysed in two cultivated genotypes of tomato submitted to PRD and conven- 
tional deficit irrigation (V50) to study the effects of these irrigation techniques on leaf and root ABA concentration, gas exchange and WUE. The aim of the work was also to analyse the response of two different tomato genotypes to the PRD technique application.

\section{Materials and methods}

The experiment was conducted at the University of Basilicata (Potenza, Italy), under controlled conditions, in a growth chamber from 9 October 2014 to 18 December 2014. The day/night temperatures were $26 / 23^{\circ} \mathrm{C}$, relative humidity $70 \%$ and mean photon flux density was about $1000 \mu \mathrm{mol} \mathrm{m} \mathrm{m}^{-2} \mathrm{~s}^{-1}$ at plant height with a $16-\mathrm{h}$ photoperiod. After the germination of seeds of Lycopersicon esculentum Mill. cv Ponderosa and cv Giallo tondo di Auletta, seedlings were transferred into plastic boxes $(40 \mathrm{~cm}$ length $\times 10 \mathrm{~cm}$ width $\times 60 \mathrm{~cm}$ height) filled with field soil with the following characteristics: sand 76.5\%, silt 16.2\%, clay 6.7\%; pH 6.8; N $1.9 \mathrm{~g} \mathrm{~kg}^{-1}$; phosphates $\left(\mathrm{P}_{2} \mathrm{O}_{5}\right) 50.3 \mathrm{~g} \mathrm{~kg}^{-1}$; potassium oxide $\left(\mathrm{K}_{2} \mathrm{O}\right) 1430 \mathrm{~g} \mathrm{~kg}^{-1}$. Gravimetric soil water was $29.5 \%$ dry weight (DW) at field capacity and $11.7 \% \mathrm{DW}$ at the theoretical wilting point (determined in the lab at -0.03 and $-1.5 \mathrm{MPa}$, respectively). Two cultivars and three irrigation treatments were compared in a completely randomised factorial experimental design with three replications. The cultivars were both yellow tomatoes with long-time storage: Ponderosa and Giallo tondo di Auletta. Irrigation treatments were the following: a control-full irrigation, in which $100 \%$ of evapotranspiration was restored (V100); a conventional deficit irrigation in which $50 \%$ of the amount of water supplied to V100 was supplied (V50); and plants where the root system was split into two parts, such that each half was planted in a plastic-bag compartment (PRD). In PRD, one compartment was watered as in V50 and the other compartment was allowed to dry, and thereafter irrigation was switched between sides. Plants were kept fully watered (field capacity) for about two weeks until five leaves were fully expanded and roots well established. Plants were fertilised with Hoagland solution $\left(2.53 \mathrm{mM} \mathrm{KNO}_{3}, 0.75 \mathrm{mM} \mathrm{Ca}\left(\mathrm{NO}_{3}\right)_{2} \cdot 4 \mathrm{H}_{2} \mathrm{O}, 0.50 \mathrm{mM}\right.$ $\mathrm{NH}_{4} \mathrm{H}_{2} \mathrm{PO}_{4}, 0.50 \mathrm{mM} \mathrm{MgSO} \cdot \cdot 7 \mathrm{H}_{2} \mathrm{O}, 4.10 \mathrm{mM} \mathrm{FeSO}{ }_{4} \cdot 7 \mathrm{H}_{2} \mathrm{O}, 2.03$ $\mathrm{mM} \mathrm{Na}$-EDTA, $11.58 \mathrm{mM} \mathrm{H}_{3} \mathrm{BO}_{3}, 2.28 \mathrm{mM} \mathrm{MnCl}_{2} \cdot 4 \mathrm{H}_{2} \mathrm{O}, 0.08$ $\mathrm{mM} \quad \mathrm{CuSO}_{4} \cdot 5 \mathrm{H}_{2} \mathrm{O}, \quad 0.15 \mathrm{mM} \quad \mathrm{H}_{2} \mathrm{MoO}_{4} \cdot \mathrm{H}_{2} \mathrm{O}, \quad 0.40 \mathrm{mM}$ $\mathrm{ZnSO}_{4} \cdot 7 \mathrm{H}_{2} \mathrm{O}$ ). During the crop cycle, soil water content was monitored by gravimetric method. Evapotranspiration was calculated from the difference in pot weights between successive days, and tomato plants were watered twice a week. All pots were rotated within the growth chamber to prevent microclimate effects. Leaf water potential $(\Psi)$ was measured from the beginning of the irrigation treatments on the youngest uppermost fully expanded leaf of three plants per treatment at midday using the pressure chamber technique (Scholander pressure chamber), according to Scholander et al. (1965). Measurements of leaf area, dry matter (DM) and chlorophyll content were made at the end of the experiment $[70$ days after transplanting (DAT)]. In particular, leaf area was measured by a surface electronic detector (Model 3100; LI-COR Inc., Lincoln, NE, USA) and DM was obtained drying the samples in a ventilated oven at $75^{\circ} \mathrm{C}$ until constant weight. Water use efficiency (expressed in $\mathrm{g} \mathrm{L}^{-1}$ ) at the plant level was calculated as the ratio between DM and plant water use obtained from total irrigation volume applied to each irrigation treatment. Chlorophyll content was measured by a chlorophyll meter soil-plant analyses development (SPAD)-502 (Konica Minolta, Osaka, Japan) at 50 DAT, from the apical leaflet of the youngest fully expanded leaf. The mean values were calculated using the internal function of the chlorophyll meter and expressed in SPAD units. In all cases, the value of three replicates $(n=3)$ for each experimental treatment was taken. The correlation between total chlorophyll content and SPAD was verified in plants grown under experimental radiation conditions. Net photosynthesis (A), transpiration $(\mathrm{E})$, stomatal conductance $\left(\mathrm{g}_{\mathrm{s}}\right)$ and intercellular $\mathrm{CO}_{2}$ concentration $\left(\mathrm{C}_{\mathrm{i}}\right)$ were measured using a LI6400 portable photosynthesis system equipped with a $2-\mathrm{cm}^{2}$ chamber and 6400-40 LED light source (LI-COR Inc.), operating at 380 ppm ambient $\mathrm{CO}_{2}$ concentration. Analyses were carried out between 12:00 and 14:00 h (solar time) under saturating light conditions (photosynthetic active radiation, PAR about $1500 \mu \mathrm{mol}$ photons $\mathrm{m}^{-2} \mathrm{~s}^{-1}$ ). These measurements were made on 22 and 50 days after transplantation (DAT) concomitant with the measurements of leaf water potential $(\Psi)$. Instantaneous water use efficiency $\left(\mathrm{WUE}_{\mathrm{i}}\right)$ was calculated as the ratio between assimilated $\mathrm{CO}_{2}$ and transpiration flow (Medrano et al., 2015).

The measurement of ABA level was made in leaves and roots at 50 and 70 DAT. Frozen foliage and root samples $(75 \mathrm{mg})$ were grounded into powder with liquid nitrogen with a mortar and pestle, and put in a tube. To each tube, $0.75 \mathrm{~mL}$, extraction solvent (2propanol $/ \mathrm{H}_{2} \mathrm{O} / \mathrm{HCL} 37 \% ; 2: 10: 002, \mathrm{v} / \mathrm{v} / \mathrm{v}$ ) was added. The tubes were shaken at a speed of $100 \mathrm{rpm}$ for $30 \mathrm{~min}$ at $4^{\circ} \mathrm{C}$. To each tube, $0.75 \mathrm{~mL}$, of dichloromethane was added, and then the samples were shaken for $30 \mathrm{~min}$ at $4^{\circ} \mathrm{C}$ and centrifuged at $13,000 \mathrm{~g}$ for 5 min. After centrifugation two phases were formed, with plant debris between the two layers, so $400 \mu \mathrm{L}$ of the solvent from the lower phase was transferred using a Pasteur pipette into a screwcap vial, and the solvent mixture was concentrated using a evaporator with nitrogen flow. Finally, the samples were re-dissolved in $0.210 \mathrm{~mL}$ methanol and stored at $-20^{\circ} \mathrm{C}$ before quantitative analysis. To quantify the ABA content, known amounts of pure standard were injected into the HPLC system and an equation, correlating peak area to ABA concentration, was formulated.

Data were analysed using analysis of variance (ANOVA) and treatment means were separated by Tukey's Student range test at $\mathrm{P} \leq 0.05$. All analyses were performed by the Minitab (version 17.1.0) software.

\section{Results}

\section{Leaf abscisic acid}

Leaf ABA content is reported in Figure 1. At the first measurement (50 days after transplanting), the cultivar effect was significant. In Ponderosa, ABA content was lower than in Auletta (Figure 1A). Significant differences were also observed as a function of irrigation treatment: the highest ABA values were observed in PRD and V50, compared to V100 (Figure 1B). At 70 days after transplanting, irrigation significantly affected leaf ABA. Higher levels of ABA were measured in PRD compared to V100, while V50 showed intermediate values, not significantly different from either of the other treatments (Figure 1C).

For root abscisic acid concentration (Figure 1D), the interaction between variety and irrigation treatment was significant. In the Auletta cultivar, root ABA content in V100 was significantly lower than in the deficit irrigation treatments, which were not different from each other. For Ponderosa, root ABA concentration in PRD reached significantly higher values than both V50 and V100, and a lower value of V100 was not significantly different from that of V50. 


\section{Gas exchange}

Measurements of single-leaf gas exchange (assimilation rate, $\mathrm{CO}_{2}$ concentration stomatal, conductance to $\mathrm{H}_{2} \mathrm{O}$ and transpiration rate) were taken at 22 DAT (Figure 2) and 50 DAT (Figure 3) after transplanting. According to two-way ANOVA test, at 22 DAT (Figure 2), V50 in Ponderosa showed lower values of photosynthetic rate than in PRD, and intermediate values between PRD and V100 for transpiration and conductance. In Auletta, PRD showed lower stomatal conductance and transpiration rate than V100, and this caused a higher $\mathrm{WUE}_{\mathrm{i}}$. Successively, at 50 DAT (Figure 3), as regards photosynthesic rate $(a)$ and conductance, only the effect of irrigation treatments was significant. The lowest values of photosynthesis, stomatal conductance (Figure 3A and B) and intercellular $\mathrm{CO}_{2}$ concentration (Table 1) were observed in PRD and V50, compared to V100. Assimilation rate, stomatal conductance and intercellular $\mathrm{CO}_{2}$ concentration decreased by 22,36 and $12 \%$, respectively, in PRD, V50 and V100 (Figure 3 and Table 1). At 50
DAT, the highest transpiration values were observed in V100 for both varieties (Ponderosa and Auletta), but they were significantly different only in V50 in Ponderosa, and in PRD in Auletta (Figure $3 \mathrm{C})$. Regarding $\mathrm{WUE}_{\mathrm{i}}$, the interaction between irrigation treatment and varieties was significant. In Auletta, $\mathrm{WUE}_{\mathrm{i}}$ was significantly higher for the PRD treatment with respect to V100, whereas in Ponderosa it was significantly higher in V50 with respect to PRD (Figure 3D).

Figure 4 shows the relationship between ABA concentration and stomatal conductance. A significant inverse correlation was found between the leaf ABA concentration and $g_{\mathrm{s}}\left(\mathrm{r}^{2}=0.4 ; \mathrm{P}<0.01\right)$. Referring to total chlorophyll content (SPAD values) measured at 50 DAT, the effects of irrigation treatments and variety were both significant. The higher value of total chlorophyll content was observed in Ponderosa variety (Table 1), while, as regards deficit irrigation treatments, the highest value was detected in PRD e V50 (50 and 51 SPAD values, respectively) (Table 1).

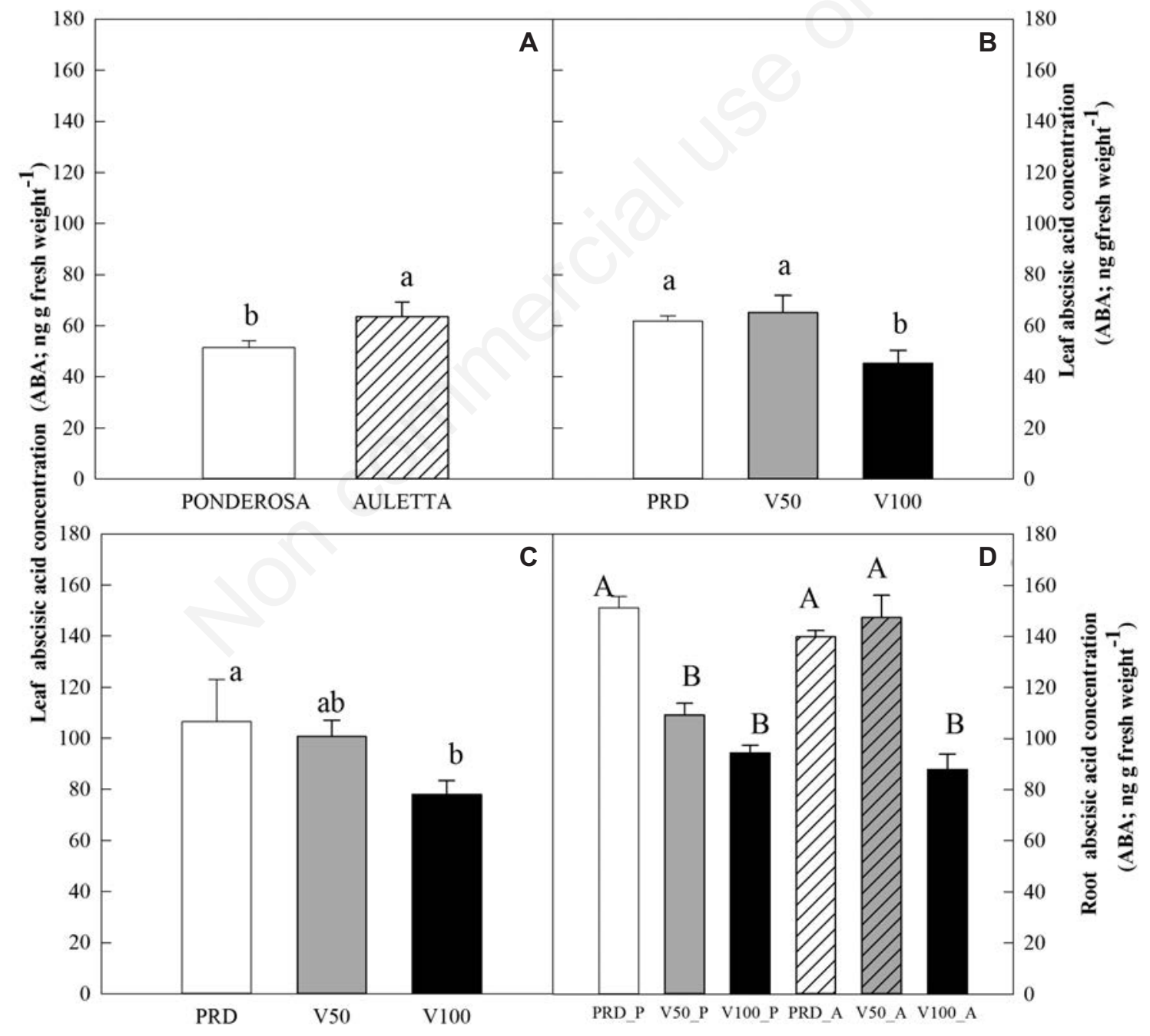

Figure 1. Abscisic acid (ABA) concentration in leaves measured 50 days ( $A$ and $B)$ and 70 days $(C)$ after transplantation and $A B A$ concentration in roots measured 70 days $(\mathrm{D})$ after transplantation in tomato plants subjected to partial root drying (PRD) and deficit irrigation (V50). Mean values ( $\mathrm{n}=3$ ) within a column followed by different lowercase and uppercase letters are significantly different at $\mathrm{P}<0.05$ and $\mathrm{P}<0.01$, respectively, according to Tukey's Student range test. 


\section{Leaf water potential}

Leaf $\Psi$ was measured twice during the experiment (at 50 and 70 DAT). The value of $\Psi$ at 50 DAT was lower in V100, but differences were not significant (Figure 5A), while the values at 70 DAT in PRD and V50 were significantly higher than in V100 (Figure 5B).

\section{Water use efficiency and soil water content}

Significant differences were also observed on WUE calculated at the plant level $\left(\mathrm{g} \mathrm{L}^{-1}\right.$ ) (Table 2). PRD and V50 in Ponderosa showed the highest values, and PRD the lowest in Auletta significantly different from Ponderosa value (Table 2). In both PRD and V50, for both varieties it was possible to save on average $46 \%$ of water, compared to V100 (Table 2). At the end of the experiment, the highest soil water content was measured in V100, while the lowest value was measured in V50 for both varieties (data not shown).

\section{Leaf area and dry matter}

Significant differences were observed in the leaf area (LA) related to both varieties and irrigation treatments. Leaf area was significantly higher in V100, compared to deficit irrigation treatments, and it was always higher in Ponderosa (Table 3). Irrigation treatments and variety significantly affected above-ground plant dry biomass, that was significantly reduced in PRD and V50, compared to V100. Differences in DM were related to the variety, as Ponderosa accumulated 20\% more DM than Auletta (Table 3). There were also great differences between the two variety in relation to the water regime in terms of DM (Table 3).
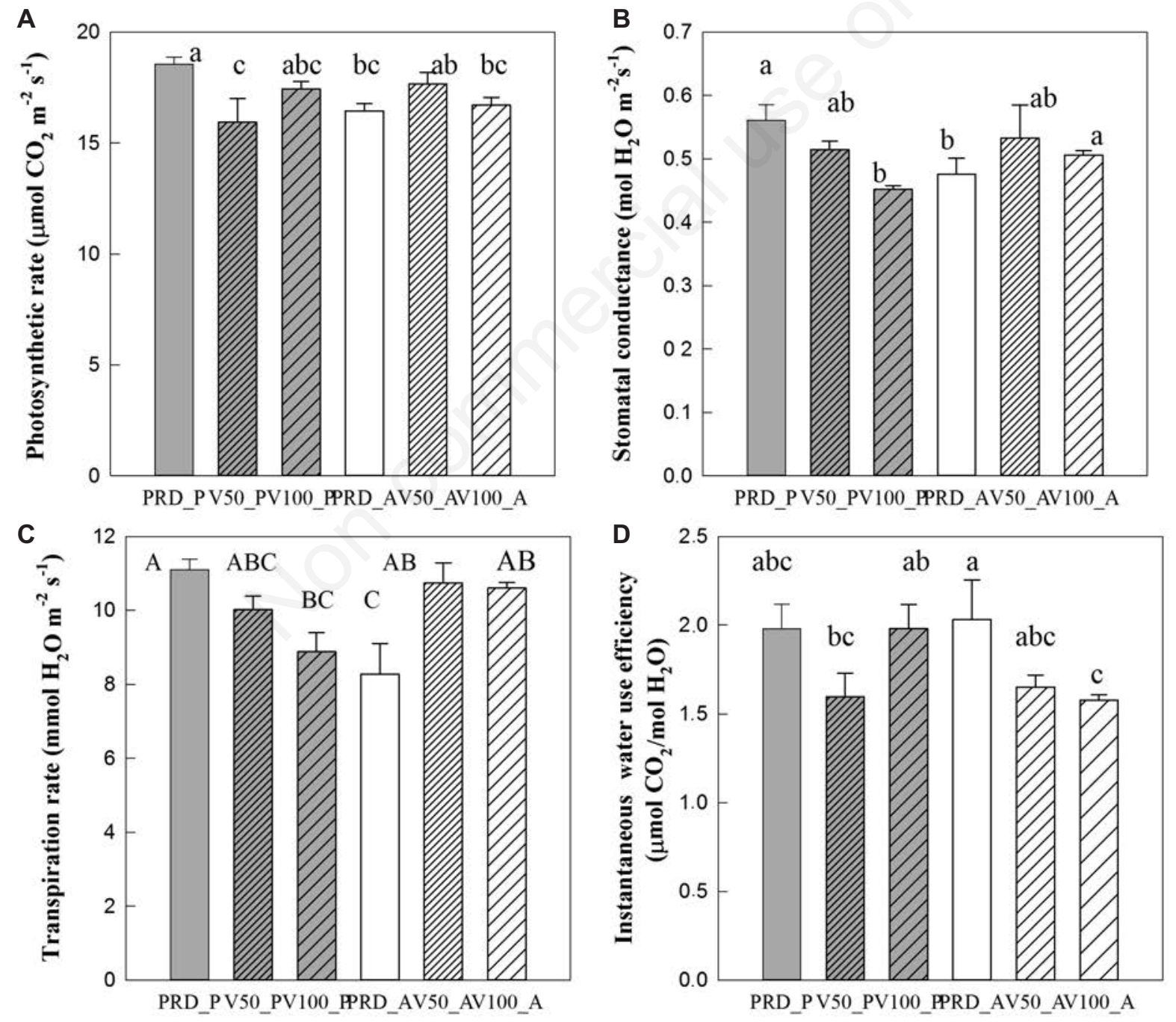

Figure 2. Photosynthetic rate (A), stomatal conductance (B), transpiration rate (C) and instantaneous water use efficiency (D) measured 22 days after transplanting in leaves of tomato plants subjected to partial root drying (PRD) and deficit irrigation (V50). Mean values $(n=3)$ within a column followed by different lowercase and uppercase letters are significantly different at $P<0.05$ and $P<0.01$, respectively, according to Tukey's Student range test. 
Table 1. Intercellular $\mathrm{CO}_{2}$ concentration and chlorophyll content measured at 50 days after transplanting.

\begin{tabular}{|c|c|c|c|c|c|c|}
\hline & Ponderosa & $\begin{array}{c}\mathrm{Ci} \\
\text { ol } \mathrm{CO}_{2} \mathrm{~m}^{2} \\
\text { Auletta }\end{array}$ & Mean & Ponderosa & $\begin{array}{c}\text { SPAD } \\
\text { Auletta }\end{array}$ & Mean \\
\hline PRD & 309.3 & 256.7 & $283^{b}$ & 52.9 & 47.5 & $50.2^{\mathrm{ab}}$ \\
\hline V50 & 261.3 & 307.3 & $284.3^{\mathrm{ab}}$ & 52.7 & 49.6 & $51.1^{\mathrm{a}}$ \\
\hline V100 & 318.7 & 325.3 & $322^{\mathrm{a}}$ & 48.7 & 45.1 & $46.9^{b}$ \\
\hline Mean & 296.4 & 296.4 & - & $51.4^{\mathrm{a}}$ & $47.4^{\mathrm{b}}$ & - \\
\hline
\end{tabular}

$\mathrm{C}_{\mathrm{i}}$, intercellular $\mathrm{CO}_{2}$ concentration; SPAD, soil-plant analyses development; PRD, partial root drying; $\mathrm{V} 50$, plants in which $50 \%$ of the amount of water given to V100 was supplied; $\mathrm{V} 100$, plants receiving an amount of water equivalent to $100 \%$ of plant evapotranspiration. a,bValues within and between columns followed by different letters are significantly different at $\mathrm{P}<0.01$ and $\mathrm{P}<0.05$ according to Tukey method. Number of replicates $=3$.

Table 2. Irrigation water use and water use efficiency.

\begin{tabular}{lcccccc} 
& \multicolumn{3}{c}{$\begin{array}{c}\text { Irrigation water use } \\
\text { (L plant }\end{array}$} & & & WUE $\left(\mathrm{g}^{-1}\right)$ \\
& Ponderosa & Auletta & Mean & Ponderosa & Auletia & Mean \\
PRD & 10 & 9 & $9.5^{\mathrm{a}}$ & $1.5^{\mathrm{a}}$ & $1.1^{\mathrm{b}}$ & 1.3 \\
V50 & 10 & 9 & $9.5^{\mathrm{a}}$ & $1.5^{\mathrm{a}}$ & $1.3^{\mathrm{ab}}$ & 1.4 \\
\hline V100 & 18 & 17 & $17.5^{\mathrm{b}}$ & $1.2^{\mathrm{ab}}$ & $1.3^{\mathrm{ab}}$ & 1.3 \\
Mean & 14 & 13 & - & 1.4 & 1.2 & - \\
\hline
\end{tabular}

$\mathrm{C}_{\mathrm{i}}$, intercellular $\mathrm{CO}_{2}$ concentration; SPAD, soil-plant analyses development; PRD, partial root drying; V50, plants in which 50\% of the amount of water given to V100 was supplied; V100, plants receiving an amount of water equivalent to $100 \%$ of plant evapotranspiration. a,bValues between columns followed by different letters are significantly different at $\mathrm{P}<0.01$ and $\mathrm{P}<0.05$ according to Tukey method. Number of replicates $=3$.
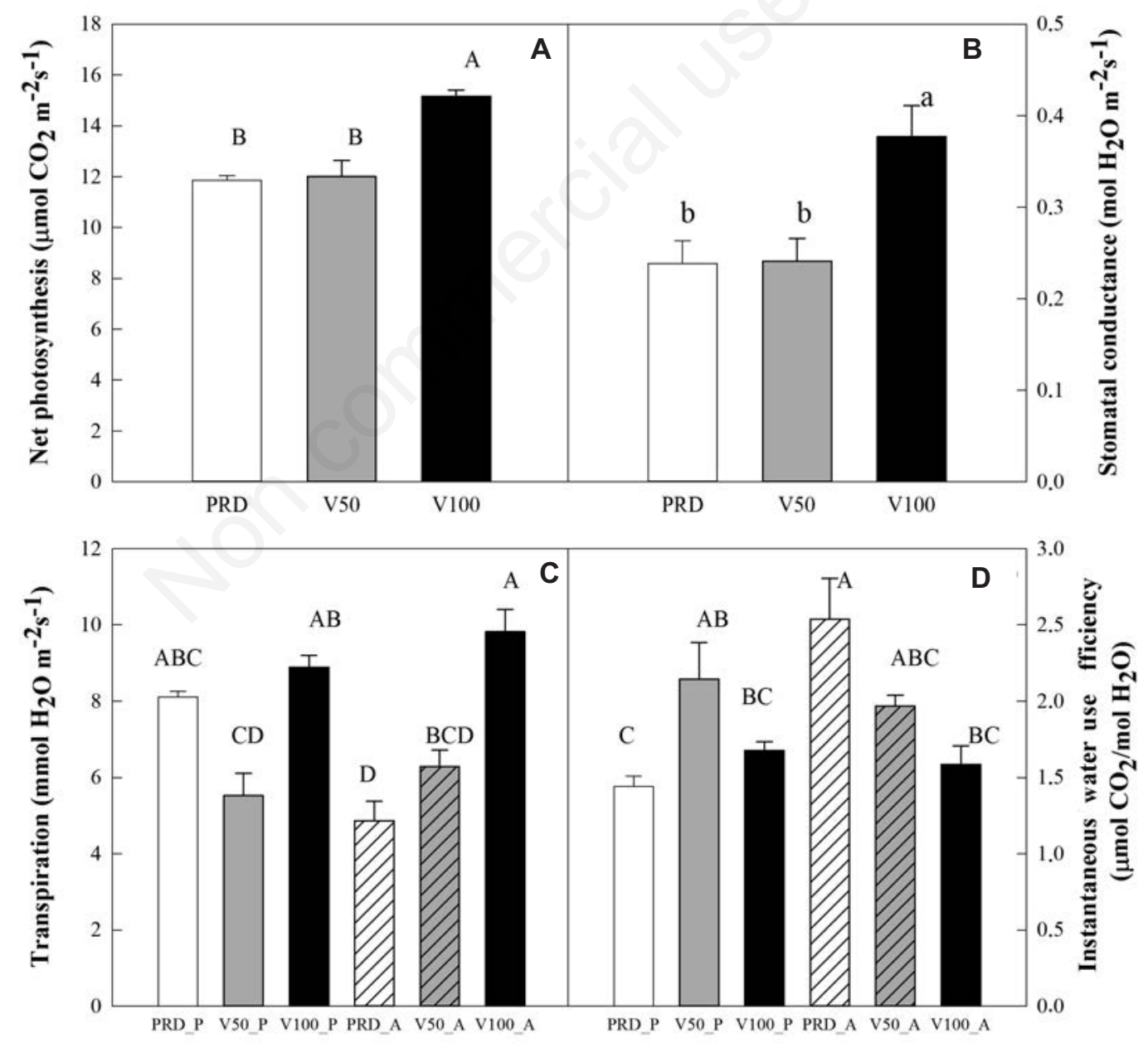

Figure 3. Net photosynthesis (A), stomatal conductance (B), transpiration (C) and instantaneous water use efficiency (D) measured 50 days after transplanting in leaves of tomato plants subjected to partial root drying (PRD) and deficit irrigation (V50). Mean values $(\mathrm{n}=3)$ within a column followed by different lowercase and uppercase letters are significantly different at $\mathrm{P}<0.05$ and $\mathrm{P}<0.01$, respectively, according to Tukey's Student range test. 


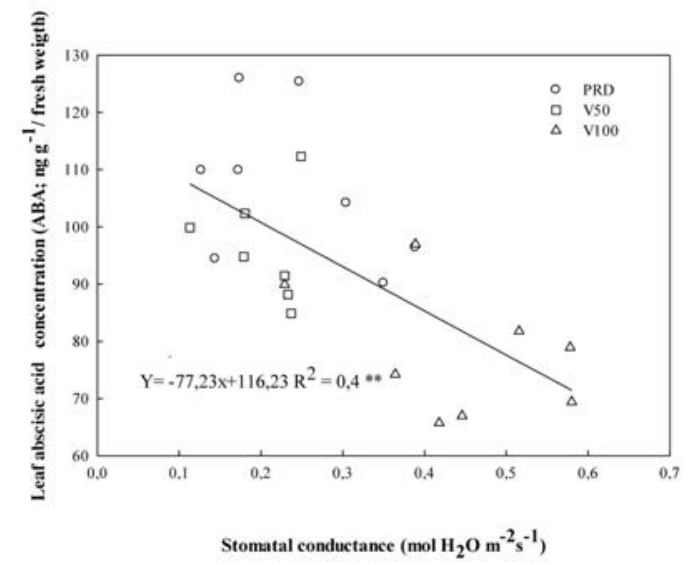

Figure 4. Relationship between leaf abscisic acid and stomatal conductance: values measured at $\mathbf{5 0}$ days after transplanting.

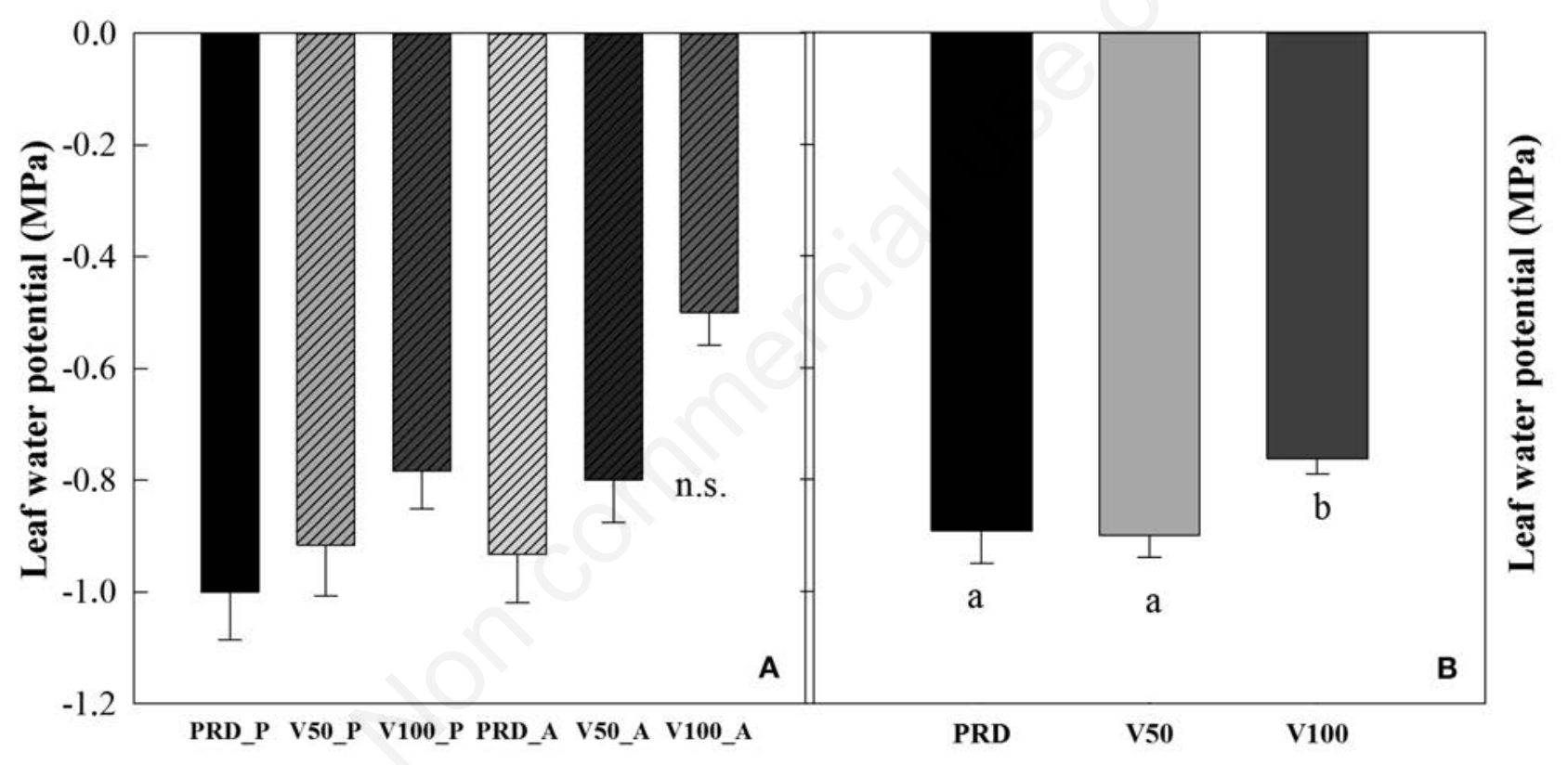

Figure 5. Leaf water potential measured 50 (A) and 70 days $(\mathrm{B})$ after transplantation. Bars are mean values $(\mathrm{n}=3) \pm$ standard error, different lowercase and uppercase letters on bars indicate significant difference at $\mathrm{P}<0.05$ and $\mathrm{P}<0.01$, respectively, according to Tukey's Student range test.

Table 3. Leaf area and above ground dry matter measured at 70 days after transplanting.

\begin{tabular}{|c|c|c|c|c|c|c|}
\hline & \multicolumn{3}{|c|}{$\mathrm{LA}\left(\mathrm{cm}^{2}\right)$} & \multicolumn{3}{|c|}{ DM (g plant $\left.{ }^{-1}\right)$} \\
\hline & Ponderosa & Auletta & Mean & Ponderosa & Auletta & Mean \\
\hline PRD & $722^{b c}$ & $607^{c}$ & 665 & 14.7 & 8.4 & $11.5^{\mathrm{b}}$ \\
\hline V50 & $660^{\mathrm{bc}}$ & $585^{\mathrm{c}}$ & 622 & 14.8 & 11.6 & $13.2^{\mathrm{b}}$ \\
\hline V100 & $1456^{\mathrm{a}}$ & $754^{\mathrm{b}}$ & 1105 & 21.9 & 21.3 & $21.6^{\mathrm{a}}$ \\
\hline Mean & 946 & 649 & - & $17.1^{\mathrm{a}}$ & $13.8^{\mathrm{b}}$ & - \\
\hline
\end{tabular}

LA, leaf area; DM, dry matter; PRD, partial root drying; V50, plants in which 50\% of the amount of water given to V100 was supplied; V100, plants receiving an amount of water equivalent to 100\% of plant evapotranspiration. ${ }^{\mathrm{a}-\mathrm{c} V}$ Values within and between columns followed by different letters are significantly different at $\mathrm{P}<0.01$ and $\mathrm{P}<0.05$ according to Tukey method. Number of replicates $=3$. 
with respect to Ponderosa variety, and this likely means that there is a different behavior between tomato cultivar as regards to leaf ABA accumulation into leaf tissue (Figure 1A). Roots in tomato submitted to PRD and V50 treatments produced more ABA than under normal condition, as also shown by other authors (Davies and Zang, 1991), but we also showed the interaction effect irrigation $\times$ variety (Figure 1D). This result confirms our hypothesis that there are varietal differences in root ABA biosynthesis and accumulation under conventional deficit irrigation (V50). Some authors (Topcu et al., 2007) showed that ABA xylem concentration is actually higher in deficit irrigation treatment than in PRD plants before irrigation events, while after irrigation the opposite occurs. It seems that ABA xylem concentration and accumulation into leaf and root tissue of PRD and V50 plants are very dynamic, the results being very much dependent on the sampling time. Gas exchange parameters were affected less during initial part of the experiment (22 DAT; Figure 2), while later (50 DAT; Figure 3) both photosynthesis and stomatal conductance where significantly affected. Our results on photosynthesis are in disagreement with Campos et al. (2009) and Zegbe et al. (2004), who found only a small reduction in the assimilative process under PRD conditions. These discrepancies might be related to the different experiment conditions: it is known that cultivar and weather conditions significantly impact the results of PRD experiments (Zegbe and Behboudian, 2008). Notwithstanding the great reduction of stomatal conductance that we measured at 70 DAT is in agreement with other studies on tomato (Campos et al., 2009; Zegbe et al., 2004; Nardella et al., 2012). Moreover it is related to the leaf ABA accumulation as shown by the linear regression between these two parameters (Figure 4). Due to stomatal closure we measured a significant reduction in transpiration rate, which was more pronounced in the Auletta variety under PRD conditions. As a direct effect of this reduction $\mathrm{WUE}_{\mathrm{i}}$ was higher in Auletta variety than in Ponderosa, expecially at 70 DAT, and this result shows in clear way the existence of differences between cultivars in terms of response to PRD irrigation technique. As expected we did not measure any change of plant water status during the initial part of the experiment, when tomato plant were subjected only to a mild stress, while later plant water status was affected (Figure 5A and B) by treatments. In addition to the chemical signal, hydraulic signal is also involved, but usually a balance between them occur in PRD treatments since tomato roots on the wetted side absorb enough water to keep high shoot water potential while tomato roots in the dry side produce ABA to allow a reduction in stomatal conductance. In this way $\mathrm{WUE}_{\mathrm{i}}$ increases, as shown also by other authors (Zegbe et al., 2004; Tahi et al., 2007). Our results on PRD impact on leaf area development and plant growth (Table 3) are consistent with other studies (Campos et al., 2009; Sobeih et al., 2004). Greater Leaf Area in Ponderosa than Auletta variety is also related to the genotype. Ponderosa has a typical habit characterised by a high leaf number and leaf area (Perniola et al., 1993; Miccolis et al., 1999). Leaf area was lower in PRD and V50 treatment than fully irrigated treatment as was total DM. Water use efficiency expressed as total DM produced per L of irrigation water applied was higher in Ponderosa cultivar under PRD treatment than Auletta cultivar (Table 2). There is discrepancy between $\mathrm{WUE}_{\mathrm{i}}$ and water use efficiency calculated at the plant level on Ponderosa due to the different nature of the two indices: the former is an instantaneous measurement at leaf level, whereas the latter represents the integration of leaf area development, leaf photosynthesis and crop growth over all the experiment period. In both cultivars the increase in $\mathrm{WUE}_{\mathrm{i}}$ with PRD reflects the integration of instantaneous gas exchange measurements, which showed a larger decrease in tran- spiration relative to the decrease in $\mathrm{CO}_{2}$ assimilation in accompanying stomatal closure. The reduction in the water applied by irrigation, which was of $46 \%$ in both PRD and V50 treatment, was a consequence of the water regime applied, and it is of great importance for irrigation in semi-arid environment. The use of methods of controlled irrigation, as PRD, leads to optimised water use by stomata that means an increase of WUE without a significant decrease in growth of tomato (Chaves and Oliveira, 2004) as we observed in our experiment. However, equal improvement of WUE by PRD and DI treatments means that irrigation volume rather than irrigation methods is more important in determining crop growth, as was also suggested by several authors (Fernández et al., 2006; Tahi et al., 2007; Nardella et al., 2012). The Ponderosa yellow long-storage tomato variety is known as moderately resistant to water deficit (Perniola et al., 1993; Miccolis et al., 1999) and perhaps for this moderate drought resistance it lends itself to the application of deficit irrigation. Values of WUE of the local Auletta variety and of Ponderosa variety were not significantly different from those in well watered and conventional deficit irrigation, nevertheless, Auletta showed lower values of WUE in PRD conditions which means that compared to Ponderosa, it lends itself less to the application of this irrigation technique (Table 2).

\section{Conclusions}

It can be concluded that PRD presented some advantages in regulating leaf gas exchange and crop growth, compared to conventional deficit irrigation (V50). These short-term positive aspects at the leaf level did not cause marked differences at the whole-plant level in the long term, as both treatments resulted in similar crop growth and WUE. Moreover, differences between tomato cultivars, in terms of WUE to PRD irrigation technique, highlighted that the choice of variety is crucial for the success of this irrigation technique. Our results indicate that there is still space to optimise the PRD strategy, so improving the cumulative physiological effects of the root-sourced signaling system. Further studies with different varieties and sampling time for ABA accumulation into crop tissue are therefore required.

\section{References}

Ahmadi SH, Andersen MN, Plauborg F, Poulsen RT, Jensen CR, Sepaskhah AR, Hansen S, 2010. Effects of irrigation strategies and soils on field grown potatoes: gas exchange and xylem [ABA]. Agri. Water Manage. 97:1486-94.

Bravdo BA, 2005. Physiological mechanisms involved in the production of non-hidraulic root signals by partial rootzone drying: a review. Acta Hortic. 689:267-76.

Campos H, Trejo C, Pena Valdivia BC, Ramirez-Ayala C, Sanchez-Garcia P, 2009. Effect of partial rootzone drying on growth, gas exchange, and yield of tomato (Solanum lycopersicum L.). Sci. Hortic. 120:493-9.

Chaves MM, Oliveira MM, 2004. Mechanisms underlying plant resilience to water deficits: prospects for water-saving agriculture. J. Exp. Bot. 55:2365-84.

Davies WJ, Bacon MA, Thompson DS, Sobeih W, Rodriguez LG, 2000. Regulation of leaf and fruit growth in plants growing in drying soil: exploitation of the plants' chemical signaling 
system and hydraulic architecture to increase the efficiency of water use in agriculture. J. Exp. Bot. 51:1617-26.

Davies WJ, Wilkinson S, Loveys B, 2002. Stomatal control by chemical signaling and the exploitation of this mechanism to increase water use efficiency in agriculture. New Phytol. 153:449-60.

Davies WJ, Zhang JH, 1991. Root signals and the regulation of growth and development of plants in drying soil. Annu. Rev. Plant Phys. 42:55-76.

De Fraiture C, Wichelns D, Rockstrom J, Kemp-Benedict E, Eriyagama N, Gordon LJ, Hanjra MA, Hoogeveen J, HuberLee A, Karlberg L, 2007. Looking ahead to 2050: scenarios of alternative investment approaches. In: D. Molden (ed.) Water for food, water for life: a comprehensive assessment of water management in agriculture. comprehensive assessment of water management in agriculture. International Water Management Institute, London, UK. pp. 91-145.

Dodd IC, 2003. Hormonal interactions and stomatal responses. J. Plant Growth Regul. 22:32-46.

Fernández JE, Díaz-Espejo A, Infante JM, Durán P, Palomo MJ, Chamorro V, Girón IF, Villagarcía L, 2006. Water relations and gas exchange in olive trees under regulated deficit irrigation and partial rootzone drying. Plant Soil. 284:273-91.

Giorgi F, Lionello P, 2008. Climate change projections for the Mediterranean region. Global Planet Change 63:90-104.

Holbrook NM, Shashidhar VR, James RA, Munns R, 2002. Stomatal control in tomato with ABA-deficient roots: response of grafted plants to soil drying. J. Exp. Bot. 53:1503-14.

Kirda C, Cetin M, Dasgan Y, Topcu S, Kaman H, Ekici B, Derici MR, Ozguven AI, 2004. Yield response of greenhouse grown tomato to partial root drying and conventional deficit irrigation. Agri. Water Manage. 69:191-201.

Lovelli S, Perniola M, Scalcione E, Troccoli A, Ziska LH, 2012. Future climate change in the Mediterranean area: implications for water use and weed management. Ital. J Agron. 7:44-9.

Loveys BR, Stoll M, Dry PR, McCarthy MG, 2000. Using plant physiology to improve the water use efficiency of horticultural crops. Acta Hortic. 537:187-97.

Medrano H, Tomás M, Martorell S, Flexas J, Hernández E, Rosselló J, Pou A, Escalona JM, Bota J, 2015. From leaf to whole-plant water use efficiency (WUE) in complex canopies: limitations of leaf WUE as a selection target. Crop J. 3:220-8.

Miccolis V, Perniola M, Rivelli AR, Candido V, 1999. Water use, water use efficiency and yield response of "long time storage" tomato (Lycopersicon esculentum Mill.). Acta Hortic.
537:789-97.

Mingo DM, Bacon MA, Davies WJ, 2003. Non-hydraulic regulation of fruit growth in tomato plants (Lycopersicon esculentum cv. Solairo) growing in drying soil. J. Exp. Bot. 54:1205-12.

Nardella E, Giuliani MM, Gatta G, De Caro A, 2012. Yield response to deficit irrigation and partial root zone drying in processing tomato (Lycopersicon esculentum Mill.). J. Agric. Sci. Technol. A 2:209-19.

Perniola M, Rivelli AR, Candido V, 1993. Yield response to water and stress indexes on tomato. Acta Hortic. 376:215-26.

Sauter A, Davies WJ, Hartung W, 2001. The long-distance abscisic acid signal in the droughted plant: the fate of the hormone on its way from root to shoot. J. Exp. Bot. 52:1991-7.

Scholander PF, Hammel HT, Bradstreet ED, Hemmingsen EA, 1965. Sap pressure in vascular plants. Science 148:339-46.

Sepaskhah AR, Ahmadi SH, 2010. A review on partial root-zone drying irrigation. Int. J. Plant Prod. 4:241-58.

Sobeih WY, Dodd IC, Bacon MA, Grierson D, Davies WJ, 2004. Long-distance signals regulating stomatal conductance and leaf growth in tomato (Lycopersicon esculentum L.) plants subjected to partial rootzone drying. J. Exp. Bot. 55:2353-63.

Tahi H, Wahbi S, Wakrim R, Aganchich B, Serraj R, Centritto M, 2007. Water relations, photosynthesis, growth, and water use efficiency in tomato plants subjected to partial rootzone drying and regulated deficit irrigation. Plant Biosyst. 141:265-74.

Taiz L, Zeiger E, 2006. Plant physiology. Sinauer Associates Inc., Sunderland, MA, USA.

Topcu S, Kirda C, Dasgan Y, Kaman H, Cetin M, Yazici A, Bacon MA, 2007. Yield response and N-fertilizer recovery of tomato grown under deficit irrigation. Eur. J. Agron. 26:64-70.

Zegbe JA, Behboudian $\mathrm{MH}, 2008$. Plant water status, $\mathrm{CO}_{2}$ assimilation, yield, and fruit quality of 'Pacific RoseTM' apple under partial rootzone drying. Adv. Hortic. Sci. 22:27-32.

Zegbe JA, Behboudian MH, Clothier BH, 2004. Partial rootzone drying is a feasible option for irrigating processing tomatoes. Agri. Water Manage. 68:195-206.

Zegbe JA, Behboudian MH, Clothier BH, 2006. Responses of 'Petopride' processing tomato to partial rootzone drying at different phenological stages. Irrig. Sci. 24:203-10.

Zegbe-Domínguez JA, Behbouidan MH, Lang A, Clothier BE, 2003. Deficit irrigation and partial rootzone drying maintain fruit dry mass and enhance fruit quality in 'Petopride' processing tomato (Licopersicon esculentum, Mill.). Sci. Hortic. 98:505-10. 